\title{
Maternal Knowledge and Use of Galactagogues in Andean Communities of Cusco, Peru
}

\author{
Madalena Monteban ${ }^{1 *}$ \\ ${ }^{1}$ Department of Anthropology, University of Georgia, Athens, Georgia, USA. \\ *madamonteban@gmail.com
}

\begin{abstract}
A commonly reported reason for early breastfeeding cessation is inadequate milk production. In response, women across the globe turn to galactagogues - substances used to increase the milk supply. Andean women have traditional knowledge about the medicinal and nutritional properties of plants and animals that are considered good to eat during breastfeeding. This research explores the maintenance and use of galactagogues, and specifically the use of the Andean flicker bird, within the wider framework of breastfeeding and nutrition policies in Peru. To elicit maternal knowledge and use of galactagogues, semi-structured and free-listing interviews were conducted with 33 mothers. Data analysis calculated the frequency and percentage of women reporting each type of galactagogue. In addition, thematic codes and relevant text passages were used in an iterative analytic process to document emerging themes. Identified galactagogues included five plants and six animals. Several galactagogues included protein-rich foods such as lamb meat and the Andean flicker bird. The use of protein-rich galactagogues as solid food is reinforced by public health messages. However, galactagogues in the research communities are usually consumed as soups or drinks, which are less rich in proteins than solid meals. The potential role of liquid galactagogues in the maintenance of appropriate hydration levels during breastfeeding in an environment where safe drinking water is scarce is a new contribution to the existing literature. The results are relevant to the design of maternal and child health policies that comply with intercultural health premises that value and respect the knowledge and practices of Andean Peoples.
\end{abstract}

Received March 15, 2017

OPENӘACCESS

Accepted June 14, 2017

DOI 10.14237/ebl.8.1.2017.935

Keywords Traditional knowledge, Public health policy, Breastfeeding, Water intake, Maternal and child health, Nutrition

Copyright (C) 2017 by the author(s); licensee Society of Ethnobiology. This is an open-access article distributed under the terms of the Creative Commons Attribution-NonCommercial 4.0 International Public License (https://creativecommons.org/licenses/by-nc/4.0), which permits non-commercial use, distribution, and reproduction in any medium, provided the original author and source are credited.

\section{Introduction}

Early exclusive breastfeeding has been linked to positive health outcomes such as the prevention of chronic diseases for the mother and child, the improvement of infant's immunity, nutrient absorption, neurodevelopment, and maternal psychological well-being (American Academy of Pediatrics Section on Breastfeeding 2012). Yet the widespread adoption of breastfeeding remains challenging (Mortel and Mehta 2013). Women may experience difficulty with breastfeeding due to numerous biological, cultural, and social factors (Balogun et al. 2015).

One of the most commonly reported reasons for early breastfeeding cessation is inadequate milk production (Gatti 2008; Scott and Colin 2002; Tenfelde et al. 2013). Chan et al. (2000) reported that $44 \%$ of mothers in their Hong Kong sample of willing breastfeeders experienced postpartum hypogalactia, reduced milk production. Pharmacological therapies such as metoclopramide, oxytocin, and domperidone are sometimes used to augment breast milk production, but safety concerns have limited their use (Makari et al. 2014; Paul et al. 2015; Rossi and Giorgi 2010).

To augment breast milk production, a substantial number of women turn to galactogogues, substances thought to increase the supply of milk. Among Western Australia women who were breastfeeding, $24 \%$ reported the use of herbal galactagogues (Sim et al. 2015). In a study conducted in Switzerland and Canada, midwives reported high use of galactagogues among their patients (93\% in Switzerland and 100\% in Canada) (Winterfeld et al. 2012). In Australia, Tawia (2014) explored the perspectives and attitudes 
of breastfeeding women towards the use of herbal galactagogues. Positive experiences with using these substances linked to women's self-empowerment. Perception of breastfeeding adequacy reportedly boosted participants' confidence levels and resulted in psychological benefits.

Despite the scarcity of clinical data on the actual increase of breast milk production, many women continue to use natural galactagogues (Forinash et al. 2012; Zapantis et al. 2012). Several researchers have surveyed galactagogues in different world regions, among them, Brückner (1996) in Europe, Dandotiya et al. (2013) in India, Othman et al. (2014) in Malaysia, Bnouham (2010) in Morocco, and Froemming (2006) and Bussman and Glen (2010) in Peru. However, few efficacy studies have been conducted. A randomized clinical trial of 75 lactating women in Egypt found that palm dates (Phoenix dactylifera) and fenugreek (Trigonella foenum-graecum) herbal tea enhanced breast milk production (Sakka et al. 2014). Gbadamosi and Okolosi (2013) analyzed ten botanical galactagogues for their chemical constituents and antimicrobial activities finding that they had high protein, fiber, iron and calcium content, and antibacterial activity. In an animal study Torabi Gudarzi et al. (2008) found that cows fed with a mixture of fennel (Foeniculum vulgare) and nigella (Nigella sativa) increased daily milk yield compared to the control group. Another study showed that extracts of banana (Musa $\times$ paradisiaca) fruits increased serum prolactin levels significantly in female rats (Mahmood et al. 2012). The molecular mechanisms underlying the action of herbal galactagogues remain unknown. Recently, Liu et al. (2015) showed in animal models that herbal galactagogues may increase milk secretion by regulating mammary glands' expression and function of aquaporins (AQPs -a family of membrane proteins facilitating water movement across cell membranes). Nevertheless, the existing clinical evidence regarding the efficacy of galactagogues remains insufficient (Zapantis et al. 2012).

\section{Breastfeeding and Maternal-Child Health Policies in Peru}

The duration of breastfeeding has declined by 0.6 months in rural areas of Peru between 1986 and 2004, while an increase of 9.7 months occurred in urban areas. The duration increased by 6.3 months among mothers receiving prenatal care, and by 3.7 months among mothers who did not receive prenatal care (Lutter et al. 2011). During the previous decade, public health policies introduced institutionalized perinatal care. In 2004, health clinics in the district of Cusco adopted the Peruvian Ministry of Health's resolution Lineamientos de Nutricion Materna (Norms for Maternal Nutrition) to promote maternal and infant health (Instituto Nacional de Salud 2004). This initiative mandates that mothers receive pre- and postnatal monitoring and that they participate in nutrition workshops. Women receive information regarding health promotion and monthly rations of food consisting of rice (Oryza sativa), oil, sardines, milk, fava beans (Vicia faba) flour, quinoa (Chenopodium quinoa), amaranth (Amaranthaceae amaranthus), and oatmeal. These policies also promote the World Health Organization (WHO) guidelines for breastfeeding (WHO 1990), recommending exclusive breastfeeding until 6 months of age and complementary breastfeeding with solid food until 2 years of age. Changes introduced by the Peruvian Ministry of Health regarding maternal-child health have influenced the social relations in Indigenous Andean communities. Until recent times, mothers decided whether to access public health services or to maintain the decisionmaking regarding infant care exclusively within the home with the assistance of family members.

Mothers' breastfeeding decisions are shaped by social norms about nutrition (Dettwyler 1987; Piperata 2008). The period of lactation is energetically demanding for the mother and cultural practices such as food avoidance, decisions about when to start or end breastfeeding, or about supplementary feeding can mediate energy demands. The Andean breastfeeding mother and child live amidst nutritional norms and practices, which includes a repertoire of knowledge about plants, animals, and minerals believed to provide additional nutrients. On the other hand, cultural practices may present aspects that counter adequate nutritional intake during this period (Piperata 2008). From a public health perspective, it is of interest to develop intercultural initiatives that analyze consensus on local knowledge and practices. The use of galactagogues in the context of maternal-child health policies in Latin America has not been studied. This article examines maternal knowledge and use of natural galactagogues in rural communities of Cusco Region, Peru, within the broader context of current breastfeeding, nutrition, and public health policies.

\section{Methods}

Study Location

The research was conducted in Cuyo Grande and Chawaytire, two Indigenous rural communities in 
Cusco Region, Peru. The communities are located at 3400 and 4000 meters above sea level and have populations of 900 and 500 people, respectively. A public health clinic provides primary health care services in each community. Residents are subsistence farmers who grow potatoes (Solanum tuberosum), corn (Zea mays), and other Andean tubers and grains, and herd livestock. Residents supplement livelihoods with activities relating to crafts and seasonal migration for jobs.

\section{Data Collection}

Data collection proceeded from December 2011 to December 2013 and consisted of semi-structured interviews, observations, and free-listing techniques. Semi-structured and free-listing interviews were conducted among 18 mothers of over 45 years of age, and identified by community members as knowledgeable about breastfeeding and child rearing. Another set of semi-structured interviews was conducted among 15 younger mothers who were currently breastfeeding and represented diverse characteristics regarding educational level, number of children, household composition, household income, and religion. Purposeful sampling was used to recruit participants. The interviews explored mother's breastfeeding perceptions and experiences and the knowledge and use of galactagogues. Observations were conducted in participants' homes on four occasions, lasting 12 hours each and spanning from the child's birth until reaching one year of age. The field notes contained information regarding the dynamics of child feeding and food consumption in the family. Observations were also conducted sporadically in the two public health clinics with the aim of learning about the interplay of public health service providers with local clients.

Free-listing interviews were used to identify natural elements that mothers perceived as beneficial for breast milk production. The objective of freelisting is for informants to list as many items as they can in a domain of interest (Bernard 2011). Nonspecific prompting assisted respondents to recall additional elements.

Most participants had some degree of Spanish language skills; however, Quechua was their primary and preferred language. A native field research assistant from Cuyo Grande, who was bilingual in Quechua and Spanish, collaborated in data collection. The free-listing exercises and semi-structured interviews were audio recorded and lasted between 20 and 60 minutes. A second research assistant transcribed and translated the interviews from Quechua to Spanish. Notes were taken during interviews and used to cross-check transcriptions to assure completeness and accuracy. In addition, a Quechua language scholar from the city of Cusco checked the accuracy of the translations.

The Institutional Review Board of the University of Georgia provided ethical approval to conduct this study and participants provided their informed consent. In addition, elected officials from the participating communities provided permission to conduct the research.

\section{Data Analysis}

The analysis of interviews followed an inductive reasoning approach, using the narratives to build interpretations and meanings (Riessman 2008). Organizing concepts and categories were identified with an open codification scheme. The text coding was developed with ATLAS.ti (6.2). Thematic codes and relevant text passages were used in an iterative analytic process to document emerging themes. Each category was then analyzed in detail, cross checking coding strategies and interpretation of data between two independent analysts. Content disagreements were discussed and the emerging insights provided for refining coding frames (Barbour 2001). Emerging themes were diverse and encompassed narratives about the transmission of knowledge regarding galactagogues, description and interpretation of the forms of use, involvement of household members, and perceptions about galactagogues' effects. Specific themes included liquids, transmission of knowledge, description of forms of use, experiences with use, perceptions regarding effects, hak'acbu (Andean flicker bird) procurement, and bak'achu use. The consistency of results was cross-checked with published data (Froemming 2006), with Andean ethnomedical concepts (Graham 1997; Larme 1998; Mazzes 1968; Frisancho Pineda 2009), and through discussion with community members and research assistants (Patton 2005).

The household observation data were used to cross check the results of semi-structured interviews. Field notes from observations in health clinics were analyzed to examine the involvement of clinics' personnel in promoting the use of natural galactagogues. Free-listing data provided the frequency and percentage of each type of galactagogue. Free-list results were used to elicit from all women the type of 
preparation used for consumption of each galactagogue.

\section{Results}

Knowledge and Use of Galactagogues

Table 1 shows the results of free-listings. Mothers listed 13 galactagogues. Five animals were mentioned, among them two mammals, sheep (Ovis aries) and cow (Bos taurus); two birds, the Andean Flicker (Colaptes rupicola) bird or back'achu, and chicken (Gallus gallus domesticus); and one amphibian, the frog (Ranidae rana). Five plants were listed, quinoa, ch'uño or freeze-dried potato, an Andean tuber named raqacha (Arracacia xanthorriza), watercress (Nasturtium officinale), and fennel. Mothers also mentioned eggs and milk, and referred to the galactagogue effect of increasing the consumption of meat, soup, and food in general. The most frequently mentioned item was quinoa soup (67\% of the mothers), followed by general soup consumption (60\%). The free-listing results for mothers who were breastfeeding were similar to the listing of older mothers with the exception that mothers who were currently breastfeeding included oatmeal and did not mention frog, ch'uño, raqacha or watercress.

Galactagogues and Hydration in the Breastfeeding Period Respondents expressed awareness of the importance of breastfeeding and resorted to natural elements perceived to act as galactagogues when they thought that their breast milk supply was inadequate. In addition, observations in the local clinics showed that health personnel recommend the use of galactagogues, most often quinoa, when milk production was not sufficient.

Galactagogues were almost always mentioned in association with the manner in which they were consumed, for example, "bak'achu soup" or "quinoa drink." Most galactagogues were ingested as broths or drinks. A common practice consists of slaughtering a sheep and preparing a soup for the mother when a child is born. A local saying states that "without soup there is no milk." Soup is an essential component of any Andean meal. However, when participants mentioned soup in general as a galactagogue they referred to its increased consumption. The lactating

Table 1 Galactagogues listed by mothers in Cuyo Grande and Chawaytire, Peru ( $N=33$ ).

\begin{tabular}{lll}
\hline Form & Main Ingredient & Frequency of mention (\%) \\
\hline soup & quinoa & $22(66.6)$ \\
soup & lamb meat & $11(33.3)$ \\
soup & hak'achu (Andean flicker bird) & $10(30.3)$ \\
soup & lamb sorqan (lung) & $9(27.3)$ \\
soup & chicken & $2(6.1)$ \\
soup & ch'uño (freeze dried potato) & $2(6.1)^{*}$ \\
soup & lamb feet & $2(6.1)$ \\
soup & $k^{\prime}$ 'ayra (frog) & $1(3)^{*}$ \\
soup & raqacha (Andean root vegetable) & $1(3)^{*}$ \\
drink & milk & $17(51.5)$ \\
drink & oatmeal & $6(18.2)^{* *}$ \\
drink & fennel & $6(18.2)$ \\
drink & quinoa & $2(6.1)^{* *}$ \\
drink & oqoruru (watercress) & $1(3)^{*}$ \\
solid & quinoa & $13(39.4)$ \\
solid & meat & $6(18.2)$ \\
solid & vegetables & $3(9.1)^{* *}$ \\
solid & egg & $2(6.1)$ \\
\hline
\end{tabular}

* galactagogues mentioned only by older mothers

${ }^{* *}$ galactagogues mentioned only by currently breastfeeding mothers 
mother would thus consume one or more extra servings of a soup to support milk production.

The Andean medicinal system provides a basis for the use of liquids during the breastfeeding period. In this system, water is considered a cleansing and nourishing therapeutic element. On the other hand, dehydration and dryness are thought to impair the flow of essential body substances like milk (Bastien 1985; Hammer 2001). Another aspect of Andean medicine related to galactagogues is the use of "cold" or "hot" and "wet" or "dry" humoral elements to counter the effects of negative exposures (Frisancho 2009). To prevent illness and to ensure the flow of vital substances in the body, individuals seek to maintain a diet that balances cold/hot and wet/dry humors (Bastien 1987; Graham 1997; Hammer 2001; Mazzes 1968). Having soups or hot drinks with the expectation of increasing milk production could indicate that women attribute hypogalactia to exposure to dry or cold elements.

Thus, the galactagogues used in the Andean health system are associated with the concept of like affects, i.e. milky and watery substances help in the production of milk. Jelliffe and Jelliffe (1978) note that many of the medical techniques, preparations and rituals used throughout the world are based on the "like affects like" principle.

Knowledge and Use of the Andean Flicker Bird as a Galactagogue

The use of the hak'achu was described by the first Spanish chroniclers who stated that the Inca appreciated its breast milk production properties, and its use continues to the present time (Froemming 2006). We have not ascertained in this study that health clinic personnel recommend the use of the bak'achu as they did with quinoa. Nonetheless, knowledge and use of the bak'achu continues among older and currently breastfeeding mothers. Of the 18 older mothers interviewed, 9 heard of hak'achu but never tried it, 6 had tried it, and 3 stated that they had never heard of using hak'achu as a galactagogue. Eight of the 15 currently breastfeeding mothers interviewed had heard of the bak'achu and 7 had eaten bak'achu soup to increase milk production.

Knowledge and use of this bird emerged as an analysis theme through the semi-structured interviews' narratives. Respondents reported that they only consume bak'achu in soup, and that they perceive a positive effect and were satisfied with the results.
According to one woman ( $\geq 45$ years old), "I ate bak'achu when I did not have milk [...] it is good for having a lot of milk. I ate it when I had my first child." A younger woman recounted:

Yes, I heard about the bak'achu. I even tried it twice. I ate it in soup, more the broth than the meat. It [the milk] increased a lot, like a cow. I even wanted my milk to dry up [a bit]. With my first child, [he/she] did not breastfeed for two hours and my breasts became swollen and hard, then I lost some of the milk. That is why I ate bak'achu [soup].

Women reported knowing about the medicinal properties of the bak'achu through information provided by close relatives, often their mothers. Other family members participated in catching the bird. According to one interviewee ( $\geq 45$ years old):

When I did not have sufficient milk, bak'achu was prepared, it is like chicken soup. My husband gathered many [birds]. With my older son, I had a lot of milk, but with my younger daughter I did not have milk...then, my mother told my husband to catch a bak'achu to increase the milk and my husband brought many to prepare the soup.

Using bak'achu depends on having a particular set of knowledge and skills. This knowledge persists in the study communities, and includes information about where to find the bird, about effective trapping strategies, and about the appropriate cooking techniques that finally produce a nutritious meal. Short (1972) reported that the bird is found in the high altitude planes of Peru, Bolivia, Chile, and Argentina, burrowing under the earth or in rocky cliffs. Froemming (2006:1) reported that "for cooking it, it is toasted, ground and prepared in the form of soup."

The narratives of our respondents provide support to these references. For example, according to one woman ( $\geq 45$ years of age):

In Lloqlla [a community near the research site]...there were many [hak'achu], we used to go there at night and we trapped them near the ditches. We carried a flashlight..., they would approach us and we trapped them like hens. We trapped the fattest ones and freed the lean ones.

For other households, the location of the bird's habitat makes its use difficult. In others, knowledge 
loss precluded its use. According to an older interviewee $(\geq 45$ years of age), "We were told [about hak'achul but were not able to catch any because they live in the hills, in high places." As a younger woman reported, "My parents told me about the hak'achu, but I never tried it, I did not know how to catch it or where it lives?"

Other women reported familiarity with the properties of hak'achu but not using it in favor of other galactagogues. According to an older woman $(\geq$ 45 years of age):

Grandpa would bring me a frog from the river. Once it was cleaned we would boil it in a ceramic pot... together with lamb feet... It is good when you boil it [frog], it is like milk. I drank it because I did not have enough milk.

Consumption of this bird appears to be specifically linked to its galactagogue properties. Mothers stated that the only use of the hak'achu was to increase milk production during breastfeeding. For example, according to one woman ( $\geq 45$ years of age), "Only those [women] that do not have milk drink bak'achu [soup], if they have [milk] what would they drink it for?"

As exemplified by the above quote, participants' narratives indicated that bak'achu is used in these communities in a sustainable manner as it is not indiscriminately consumed. Similarly, Froemming (2006) reports that "the bird is not hunted in large quantity."

\section{Discussion}

The participating mothers of Cuyo Grande and Chawaytire highlighted the relevance and perceived efficacy of natural galactagogues. Most of the galactagogues mentioned were introduced through colonization and incorporated into the local pharmacopeia. The importance attributed to breastfeeding by participants is consistent with public health policies. Also in agreement with public health recommendations encouraging consumption of a protein-rich diet during lactation, most items mothers perceived to have galactagogue properties have high protein content.

However, while public health policies recommend consuming proteins in the form of solid food, women in this study perceived the use of galactagogues in soup or drink preparations and increased consumption of soups and drinks in general as essential for promoting lactation. Despite this divergence with public health policy, increased liquid consumption during breastfeeding may have a health promotion role in the Andean communities. It is recommended that water intake increases from 2.7 to 3.8 liters per day while breastfeeding (Bentley 1998; IOM 2004). Complying with water intake recommendations may have implications for people living in environments where safe drinking water is scarce. For example, Rosinger (2015) reported that in the Bolivian Amazonia, Tsimane women who were breastfeeding were more prone to dehydration than those who were not. In the Andes, individuals are exposed to high levels of solar radiation and wind and access to safe drinking water is limited. Water used in the homes comes from streams or wells. The consumption of boiled water in the form of soups or hot drinks may constitute a protective cultural adaptation, reducing the risk of dehydration and of exposure to pathogens present in untreated water supplies. The current Norms for Maternal Nutrition (Instituto Nacional de Salud 2004) promote the consumption of solid food with high protein content because nutrients are diluted in liquid preparations. However, this document does not presently expressly address need for increased water intake. It would be relevant to consider recommendations regarding liquid intake through safe preparations like soups or hot drinks among breastfeeding mothers.

The exclusion of men in the study sample is recognized as a possible limitation. This research focused on maternal knowledge and use of galactagogues. However, mothers reported learning about the use and capture of the bak'achu from male relatives. It is possible that had men been interviewed, they may have mentioned additional galactagogues or provided further insight on the use of galactagogues in the research communities.

This study provided evidence of persistence in maternal knowledge and use of natural galactagogues in Andean communities. It contributes to the existing literature by analyzing knowledge and practices in the context of public health recommendations. I offer a new contribution to the literature by highlighting the potential role of galactagogues to (1) maintain appropriate maternal hydration levels during breastfeeding, which (2) yields sufficient milk for infant nutrition and hydration in a parching environment with limited clean water. The results are relevant for the formulation of maternal-child health policies that comply with intercultural health premises (PAHO 
2008) by valuing and respecting the knowledge and practices of Andean Peoples. Previous research highlights the sometimes conflicting relationship between Andean and biomedical knowledge (Bastien 1987; Crandon-Malamud 1991; Mathez-Stiefel et al. 2012; Miles and Leatherman 2003). For example, Mathez-Stiefel et al. (2012) affirms that complementarities between Andean and biomedical health care systems are mediated by the dominance of biomedicine as a global and state-supported system. Maternalchild health policies should involve local participation and the recognition that power inequities can play a role in facilitating knowledge exchange.

\section{Acknowledgements}

I am very grateful to the communities of Cuyo Grande and Chawaytire and the mothers who participated in the research sharing their time and knowledge. My appreciation also goes to Benedicta Velásquez-Yucra and Valeria Velásquez-Yucra for their invaluable help in data collection and to the anonymous reviewers for providing exceptionally helpful comments that helped to improve this manuscript.

\section{Declarations}

Permissions: None declared.

Sources of funding: This research was supported in part by a U.S. Department of Education Foreign Language and Area Studies Fellowship.

Conflicts of Interest: None declared.

\section{References Cited}

American Academy of Pediatrics, Section on Breastfeeding. 2012. Breastfeeding and the Use of Human Milk. Pediatrics 129:e827-e841. DOI:10.1542/peds.2011-3552.

Balogun, O., A. Dagvadorj, M. Anigo, E. Ota, and S. Sasaki. 2015. Factors Influencing Breastfeeding Exclusivity During the First 6 Months of Life in Developing Countries: A Quantitative and Qualitative Systematic Review. Maternal and Child Nutrition 11:433-451. DOI:10.1111/mcn.12180.

Barbour, R. 2001. Checklists for Improving Rigour in Qualitative Research: A Case of the Tail Wagging the Dog? British Medical Journal 322:1115-1117. Available at: http://pubmedcentralcanada.ca/ pmcc/articles/PMC1120242. Accessed on November 10, 2016.
Bastien, J. W. 1985. Qollahuaya-Andean Body Concepts: A Topographical-Hydraulic Model of Physiology. American Anthropology 87:595-611. DOI:10.1525/aa.1985.87.3.02a00050.

Bastien J. W. 1987. Cross-Cultural Communication Between Doctors and Peasants in Bolivia. Social Science and Medicine 24:1109-1118. DOI:10.1016/0277-9536(87)90025-6.

Bentley, G. R. 1998. Hydration as a Limiting Factor in Lactation. American Journal of Human Biology 10:151161. DOI:10.1002/(SICI)1520-6300(1998) 10:2<151:AIDAJHB2>3.0.CO;2-O.

Bernard, H. 2011. Research Methods in Anthropology: Qualitative and Quantitative Approaches. Altamira Press, Lanham, MD.

Bnouham, M. 2010. Medicinal Plants with Potential Galactagogue Activity Used in the Moroccan Pharmacopoeia. Journal of Complementary and Integrative Medicine 7. DOI:10.2202/15533840.1268.

Brückner, C. 1996. A Survey on Herbal Galactagogues Used in Europe. In Medicam. Aliment. L'approche Ethnopharmacol, edited by E. Schroder, G. Balasard, C. Pierre, J. Fleurentin, and G. Mazars. Colloque Européen d'Ethnopharmacologie et de la 11 Conférence internationale d'Ethnomédecine, Heidelberg, Paris, France. Available at: http:/ / www.documentation.ird.fr/hor/fdi:010005528. Accessed on November 10, 2016.

Bussman, R., and A. Glen. 2010. Medicinal Plants Used in Northern Peru for Reproductive Problems and Female Health. Journal of Ethnobiology and Ethnomedicine 6:30. DOI:10.1186/1746-4269-2-47.

Chan, S. M., E. A. S. Nelson, S. S. F. Leung, and C. Y. Li. 2000. Breastfeeding Failure in a Longitudinal Post-Partum Maternal Nutrition Study in Hong Kong. Journal of Pediatrics and Child Health 36:466471. DOI:10.1046/j.1440-1754.2000.00544.

Crandon-Malamud, L. 1991. From the Fat of Our Souls: Social Change, Political Process, and Medical Pluralism in Bolivia. University of California Press, Berkeley, CA.

Dandotiya, H., G. Singh, and S. K. Kashaw. 2013. The Galactagogues Used by Indian Tribal Communities to Overcome Poor Lactation. International Journal of Biotechnology and Bioengeneering Research 4:2231-1238. Available at: https:// www.ripublication.com/ijbbr_spl/ ijbbrv4n3spl_12. Accessed on November 10, 2016. 
Dettwyler, K. A. 1987. Breastfeeding and Weaning in Mali: Cultural Context and Hard Data. Social Science and Medicine 24:633-644. DOI:10.1016/0277-9536 (87)90306-6.

Forinash, A. B., A. M. Yancey, K. N. Barnes, and T. D. Myles. 2012. The Use of Galactogogues in the Breastfeeding Mother. Annals of Pharmacotherapy 46:1392-1404. DOI:10.1345/aph.1R167.

Frisancho Pineda, D. 2009. Las Enfermedades: Su Etiología Según la Mentalidad Indígena y Popular. In Medicina Tradicional Andina: Planteamientosy Aproximaciones, edited by R. Sánchez Garrafa and R. Sánchez Garrafa. Centro de Cuzco Medicina Andina, Centro de Estudios Regionales Andinos Bartolomé de las Casas. Cusco, Perú.

Froemming, S. 2006. Traditional Use of the Andean Flicker (Colaptes rupicola) as a Galactagogue in the Peruvian Andes. Journal of Ethnobiology and Ethnomedicine 2:23. DOI:10.1186/1746-4269-2-23.

Gatti, L. 2008. Maternal Perceptions of Insufficient Milk Supply in Breastfeeding. Journal of Nursing Scholarship 40:355-363. DOI:10.1111/j.15475069.2008.00234.x.

Gbadamosi, I., and O. Okolosi. 2013. Botanical Galactogogues: Nutritional Values and Therapeutic Potentials. Journal of Applied Bioscience 61:4460. DOI:10.4314/jab.v61i0.85594.

Graham, M. A. 1997. Food Allocation in Rural Peruvian Households: Concepts and Behavior Regarding Children. Social Science and Medicine 44:1697-1709. DOI:10.1016/S0277-9536(96) 00372-3.

Hammer, P. 2001. Blood makers made of blood: Quechua Ethnophysiology of Menstruation. In Regulating Menstruation: Beliefs, Practices, Interpretations, edited by E. Van de Walle and E. P. Renne, pp. 241-253. University of Chicago Press, Chicago, MI.

Institute of Medicine, Food and Nutrition Board. 2004. Dietary Reference Intakes for W ater, Potassium, Sodium, Chloride, and Sulfate. National Academies Press, Washington, DC.

Instituto Nacional de la Salud. Centro Nacional de Alimentación y Nutrición. 2004. Lineamientos de Nutricion Materno Infantil del Perú. Centro Nacional de Alimentación y Nutrición. Ministerio de Salud, Instituto Nacional de Salud,Lima, Perú. Available at: http://repositorio.ins.gob.pe/bitstream/ handle/INS/218/CENAN-0060.pdf? sequence $=1$ \&is Allowed $=\mathrm{y}$. Accessed on November10, 2016.

Jelliffe, D. B., and E. F. P. Jelliffe. 1978. Human Milk in the Modern World. Oxford University Press, Oxford, United Kingdom, and New York, NY.

Larme, A. C. 1998. Environment, Vulnerability, and Gender in Andean Ethnomedicine. Social Science and Medicine 47:1005-1015. DOI:10.1016/S02779536(98)00162-2.

Liu, H., Y. Hua, H. Luo, Z. Shen, X. Tao, and X. Zhu. 2015. An Herbal Galactagogue Mixture Increases Milk Production and Aquaporin Protein Expression in the Mammary Glands of Lactating Rats. Evidence-Based Complementary and Alternative Medicine 2015:1-6. DOI:10.1155/2015/760585.

Lutter, C. K., C. M. Chaparro, and L. M. GrummerStrawn. 2011. Increases in Breastfeeding in Latin America and the Caribbean: An Analysis of Equity. Health Policy Plan 26:257-265. DOI:10.1093/heapol/czq046.

Mahmood, A., M. N. Omar, and N. Ngah. 2012. Galactagogue Effects of Musa x Paradisiac a Flower Extract on Lactating Rats. Asian Pacific Journal Tropical Medicine 5:882-886. DOI:10.1016/ S1995-7645(12)60164-3.

Makari, J., K. Cameron, and M. Battistella. 2014. Domperidone-Associated Sudden Cardiac Death in the General Population and Implications for Use in Patients Undergoing Hemodialysis: A Literature Review. Canadian Journal of Hospital Pharmacy 67:441-446. DOI:10.4212/ cjhp.v67i6.1407.

Mathez-Stiefel. S. L., I. Vandebroek, and S. Rist. 2012. Can Andean Medicine Coexist with Biomedical Healthcare? A Comparison of Two Rural Communities in Peru and Bolivia. Journal of Ethnobiology and Ethnomedicine 8:26. DOI:10.1186/1746-4269-8-26.

Mazzes, R. B. 1968. Hot-Cold Food Beliefs Among Andean Peasants. Journal of the American Dietetic Association 53:109-113. Available at: https:// www.cabdirect.org/cabdirect. Accessed on November 10, 2016.

Miles, A., and T. Leatherman. 2003. Perspectives on Medical Anthropology in the Andes. In Medical Pluralism in the Andes, edited by J. D. Koss-Chioino, T. Leatherman, and C. Greenway, pp. 3-15. Routledge, London, United Kingdom, and New York, NY. 
Mortel, M., and S. D. Mehta. 2013. Systematic Review of the Efficacy of Herbal Galactogogues. Journal of Human Lactation 29:154-162. DOI:10.1177/0890334413477243.

Othman, N., R. A. C. Lamin, and C. N. Othman. 2014. Exploring Behavior on the Herbal Galactagogue Usage among Malay Lactating Mothers in Malaysia. Procedia - Social and Behavioral Sciences 153:199-208. DOI:10.1016/j.sbspro.2014.10.054.

Pan American Health Organization (PAHO). 2008. Una visión de salud intercultural para los pueblos indigenas de las Américas. Available at: http://new.paho.org/ hq/dmdocuments/2009/54-

VisionSaludInterculturalPI.pdf. Accessed on November 2016.

Patton, M. Q. 2005. Qualitative Research. Sage Publications, Thousands Oaks, CA.

Paul, C., M. Zenut, A. Dorut, M. A. Coudore, J. Vein, J. M. Cardot, and D. Balayssac. 2015. Use of Domperidone as a Galactagogue Drug: A Systematic Review of the Benefit-Risk Ratio. Journal of Human Lactation 31:57-63. DOI:10.1177/0890334414561265.

Piperata, B. A. 2008. Forty Days and Forty Nights: A Biocultural Perspective on Postpartum Practices in the Amazon. Social Sciences and Medicine 67:10941103. DOI:10.1016/j.socscimed.2008.05.031.

Riessman, C. 2008. Narrative Methods for the Human Sciences. Sage, Thousand Oaks, CA. DOI:10.1017/ S1368980014003000.

Rosinger, A. 2015. Dehydration Among Lactating Mothers in the Amazon: A Neglected Problem. American Journal of Human Biology 27:576-578. DOI:10.1002/ajhb.22672.

Rossi, M., and G. Giorgi, G. 2010. Domperidone and Long QT Syndrome. Current Drug Safety 5:257-262. DOI:10.2174/157488610791698334.

Sakka, A. E. L., M. Salama, and K. Salama. 2014. The Effect of Fenugreek Herbal Tea and Palm Dates on Breast Milk Production and Infant Weight. Journal of Pediatric Sciences 6. DOI:10.17334/ jps.30658.

Scott, J. A., and W. B. Colin. 2002. Breastfeeding: Reasons for Starting, Reasons for Stopping and Problems Along the Way. Breastfeeding Review 10:13. Available at: https://search.informit.com.au. Accessed on November 102016.
Short, L. L. 1972. Systematics and Behavior of South American Flickers (Aves, Colaptes). Bulletin of the AMNH, Vol. 149. Available at: http:// digitallibrary.amnh.org/handle/2246/1198. Accessed on November 10, 2016.

Sim, T., H. Hattingh, J. Sheriff, and L. Tee. 2015. The Use, Perceived Effectiveness and Safety of Herbal Galactagogues During Breastfeeding: A Qualitative Study. International Journal of Environmental Research and Public Health 12:11050-11071. DOI:10.3390/ ijerph120911050.

Tawia, S. 2014. Breastfeeding and Herbal Galactagogues. Australian Breastfeeding Association eNewsletter. Available at: https://www.breastfeeding.asn.au/ breastfeeding-and-herbal-galactagogues. Accessed on May 12, 2016.

Tenfelde, S., R. Zielinski, and R. L. Heidarisafa. 2013. Why WIC Women Stop Breastfeeding?: Analysis of Maternal Characteristics and Time to Cessation. ICAN Infant, Child and Adolescent Nutrition 5:207-214. DOI:10.1177/1941406413492820.

Torabi Gudarzi, M., L. U. F. Qarah Guz, A. A. F. Yusefi, and H. Akbari. 2008. Investigation on to the Effect of Fennel (Foeniculum vulgare) and Nigella (Nigella sativa) on Production in Milking Cow. Available at: http:/ /agris.fao.org/agris-search/ search.do?recordID=IR2010000035. Accessed on May 12, 2016.

World Health Organization and UNICEF. 1990. On the Protection, Promotion and Support of Breastfeeding. WHO/UNICEF Policy Makers' Meeting "Breastfeeding in the 1990s: A Global Initiative", Spedale degli Innocenti, Florence, Italy. Available at: http://www.unicef.org/programme/ breastfeeding/innocenti.htm. Accessed on May 12, 2016.

Winterfeld, U., Y. Meyer, A. Panchaud, and A. Einarson. 2012. Management of Deficient Lactation in Switzerland and Canada: A Survey of Midwives' Current Practices. Breastfeeding Medicine 7:317-318. DOI:10.1089/bfm.2011.0092.

Zapantis, A., J. G. Steinberg, and L. Schilit. 2012. Use of Herbals as Galactagogues. Journal of Pharmacy Practice 25:222-231. DOI:10.1177/0897190011431636. 